\title{
PÓS-GRADUAÇÃO, PRODUÇÃo INTELECTUAL E VEÍCULO DE PUBLICAÇÃO
}

\section{POST GRADUATION, INTELLECTUAL PRODUCTION AND PUBLICATION VEHICLE}

\author{
Samir Rasslan, TCBC ${ }^{1}$ \\ Rita Barradas Barata ${ }^{2}$ \\ Joaquim José Gama Rodrigues, TCBC $^{3}$
}

Ao longo destes pouco mais de trinta anos a pós-graduação estrito-senso influenciou de forma expressiva a produção científica no país' contribuindo para seu crescimento.

Apesar das críticas eventuais à adequação desse modelo e sua aplicabilidade nas áreas clínicas, ela tem contribuído no aprimoramento dos candidatos à carreira docente. Foi sem dúvida graças a ela que todos passaram a utilizar a mesma linguagem independente da área de atuação. Discute-se metodologia científica, modelos experimentais, epidemiologia clínica, tudo girando em torno das linhas de pesquisas.

A pós-graduação foi criada com o objetivo de preparar o professor para a atividade acadêmica, de docência e pesquisa, seja esta experimental ou clínica. Assim, o produto final da pós-graduação estrito senso é o professor pesquisador.

Ao longo do tempo foram sendo aprimorados os parâmetros de avaliação, corrigindo deficiências, exigindo qualidade. Houve inquestionável melhora apesar de estarmos longe de um patamar de homogeneidade entre os diferentes programas.

A importância crescente atribuída à produção de conhecimentos científicos paulatinamente deslocou o peso da avaliação para os produtos dessa atividade.

A produção científica dos docentes responde atualmente por $30 \%$ da avaliação dos programas. Os resultados da pesquisa desenvolvida são avaliados quanto à sua coerência com a linha de pesquisa, regularidade, qualidade e quantidade.

O grande desafio para a avaliação da produção continua sendo a qualidade. Tentativas tem sido feitas e gerado algumas críticas. Mais recente- mente a CAPES optou por criar um sistema de classificação de periódicos científicos procurando qualificar a produção dos programas de pósgraduação. Os critérios propostos tem provocado intenso debate e até mesmo divergências na comunidade.

A pesquisa científica é uma atividade que deve satisfazer três características básicas: ser socialmente relevante, ou seja, seus resultados devem encontrar cedo ou tarde, aplicação na solução de problemas humanos; ser ética, porquanto, acima dos interesses científicos deve estar a preservação da dignidade humana; e, ser pautada no mérito, isto é, ser conduzida com rigor metodológico para que produza conhecimentos verdadeiros.

A garantia da relevância social será dada pelo impacto que os conhecimentos produzidos venham a ter na transformação da realidade na busca do aperfeiçoamento. A adequação ética será garantida pela submissão ao julgamento feito pela sociedade acerca dos procedimentos dos cientistas. A produção de conhecimentos verdadeiros depende da correta aplicação do método, mas também do julgamento interpares, ou seja, a verdade é construída e aquilatada no interior da comunidade da qual o cientista faz parte.

A publicação dos resultados das pesquisas em periódicos científicos busca cumprir uma dupla função: submeter os conhecimentos produzidos ao julgamento dos pares e criar uma comunidade de interesses em torno de determinada área de investigação.

Para cumprir com esses objetivos os periódicos necessitam contar com um sistema adequado de "peer-review" e possibilitar a divulgação ampla dos resultados facilitando desta forma a apropriação pelos outros membros da comunidade.

1 Professor Titular do Departamento de Cirurgia da Faculdade de Ciências Médicas de São Paulo

2 Professor Adjunto do Departamento de Medicina Social da Faculdade de Ciências Médicas da Santa Casa de São Paulo

3 Professor Titular do Departamento de Gastroenterologia da Faculdade de Medicina da Universidade de São Paulo 
Assim sendo, os periódicos científicos devem ser classificados tomando- se em conta estas necessidades. Evidentemente, periódicos indexados em bases que possibilitem acesso mais amplo aos resultados devem ser mais valorizados do que aqueles cujo acesso só será permitido a uma pequena comunidade de assinantes ou de membros de determinadas instituições.

Aqui surge o primeiro problema com relação aos critérios até agora propostos, pois a abrangência da divulgação é simplesmente avaliada pelo caráter nacional ou internacional da indexação. Tendo em vista que o Brasil é um país periférico, no qual se fala e se escreve em uma das línguas mais utilizadas no mundo - em função da sua enorme população - mas exótica aos ouvidos anglo-saxãos, será que a indexação internacional significa realmente maior amplitude de divulgação?

Certamente alguns argumentarão que a construção da ciência se beneficia do diálogo internacional o quê certamente é verdadeiro. Mas, o inverso também será verdadeiro? A ciência não se beneficia de um diálogo nacional? Por quê qualificar, a priori e sistematicamente, como mais útil o diálogo externo?

Para a pesquisa estratégica, comprometida imediatamente com a solução de problemas, alguns dos quais próprios do nosso país ou mesmo de conjunto de países em condições semelhantes, esta é uma questão crucial. Ao valorizar, quase que exclusivamente a produção destinada ao mercado internacional a ciência brasileira corre o sério risco de direcionar seus esforços apenas para a solução de problemas dos outros. Para um país com poucos recursos destinados a pesquisa, o direcionamento das investigações para prioridades externas seria uma calamidade.

Outra consequiência desastrosa decorrente dessa postura colonizada será o enfraquecimento das revistas nacionais. Os periódicos científicos, assim como, os congressos, seminários e reuniões científicas desempenham um papel crucial na criação da comunidade de interesses. A perda de expressão dos periódicos nacionais, construídos a duras penas deixará um vazio difícil de preencher na atividade cientifica brasileira.

Não se discute a importância e a necessidade de se publicar no exterior, mas mantida esta exigência o direcionamento de trabalhos para revistas "ranqueadas" no MedLine ou ISI, com reflexos na sobrevivência das revistas nacionais, representa o caminho correto?

Na realidade o que se estimula atualmente é um "salto" radical. De uma pós-graduação que publica pouco mais de $10 \%$ das teses produzidas exigese, sem uma transição gradual, a publicação em nível internacional.

Estamos subestimando por exemplo os artigos publicados em periódicos nacionais com circulação ininterrupta há décadas, lidas por uma expressiva população de pesquisadores, e que não são inferiores a outros inseridos no MedLine ou ISI.

A utilização dos conhecimentos produzidos por parte dos profissionais de saúde será bastante prejudicada tendo em vista, que uma parte considerável deles ainda não tem acesso à literatura internacional. Deste modo, o desempenho do compromisso social da ciência com a transformação da realidade ficará prejudicado.

Na falta de critérios aplicáveis de avaliação da qualidade da produção, tem sido proposta a adoção de indicadores cientométricos, tais como, o índice de impacto. Este índice, desenvolvido pelo Institute for Scientific Information (ISI) para facilitar o processo de consulta à literatura científica e fornecer aos pesquisadores a indicação de quem são seus pares, é calculado através da razão entre o número de vezes que os artigos publicados em uma revista foram citados nos últimos dois anos e o número total de artigos publicados por esta revista. Embora o fator de impacto seja considerado um parâmetro de avaliação interessante e com certa lógica, uma série de restrições vêm sendo apontadas na sua utilização. Representa mais um índice de popularidade e não necessariamente uma medida de qualidade, pois inúmeros fatores afetam o seu valor e que nada tem a ver com qualidade científica propriamente. Entre eles podem ser citados: a natureza do assunto, o campo de conhecimento, a atualidade, o número de artigos publicados, a língua, o prestígio e a antigüidade da revista.

Um artigo metodológico ou de revisão, por exemplo, tem maior probabilidade de citação do que uma pesquisa aplicada, pois pela própria natureza o assunto será útil a uma maior quantidade de pesquisadores. A dimensão da comunidade em um determinado campo de saber também determinará a freqüência de utilização de um artigo. $\mathrm{O}$ número de artigos publicados por uma revista, ainda que seja levado em conta no denominador, também terá 
influência direta sobre a probabilidade de citação. A língua da publicação terá influência direta sobre a possibilidade de citação. Apenas o prestígio da revista poderia ser tomado como indicador indireto de sua qualidade.

Usar o índice de citação para classificar a qualidade das revistas cientificas parece, portanto, uma extrapolação com conseqüências imprevisíveis. A busca pelo aperfeiçoamento constante da produção científica nacional é um objetivo louvável, mas certamente depende mais da qualidade da formação de novos pesquisadores nos programas de pósgraduação do que do índice de impacto das revistas nas quais seus resultados de investigação serão publicados.

Apesar de todas as dificuldades o Brasil foi capaz de criar um parque científico e tecnológico importante, caracterizado por formar parcela significativa de seus pesquisadores dentro das próprias fronteiras, financiar com seus próprios recursos parcela não desprezível de sua produção e absorver, de modo expressivo, os pesquisadores formados no exterior, em comparação a países com situações econômicas semelhantes às nossas.

Já é hora da comunidade científica abandonar o complexo de inferioridade próprio do nosso povo e apostar na capacidade de discernimento sem permanecer submissa a valores que supõe a tornará respeitada "lá fora".

Estas considerações refletem preocupações com um aspecto atual e de vital importância no futuro. $\mathrm{O}$ produto final da pós-graduação é a produção intelectual e a formação docente. Os programas de pós-graduação, na formação docente, devem estimular a criatividade, aprimorar o senso crítico e capacitar o docente a tornar-se um pólo gerador de conhecimentos. Esta produção, por sua vez, é sinônimo de publicação em revistas de qualidade. É necessário apenas se tomar cuidado na escolha dos critérios utilizados nessa avaliação. 